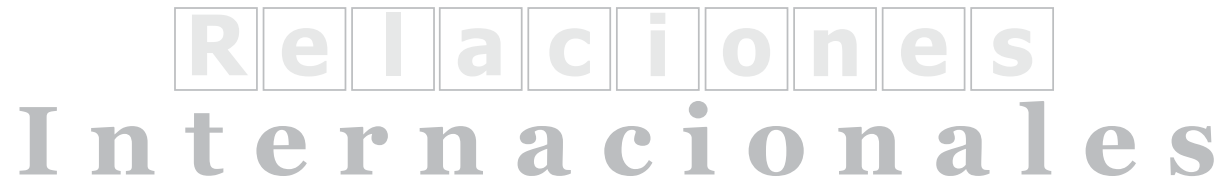





\title{
El sistema westfaliano: un análisis desde la teología política de Nicolás Gómez Dávila*
}

\author{
The Westphalian System: An Analysis from the \\ Political Theology of Nicolás Gómez Dávila
}

Tomás Felipe Molina*

Recibido: 2 de septiembre de 2015

Aprobado: 9 de marzo de 2016

Disponible en línea: 20 de diciembre de 2016

\section{Resumen}

En este artículo, se quieren analizar las características principales del sistema westfaliano a partir de la teología política que Nicolás Gómez Dávila desarrolla en Textos I. Principalmente, se intentará mostrar que los Estados westfalianos toman los atributos de Dios y sustituyen a la divinidad en el papel que tenía en la Edad Media: reclaman para sí mismos la soberanía y la fundamentación axiológica y ontológica de los elementos del sistema. A partir de lo anterior, el artículo pretende señalar y analizar varios puntos. Primero, la anarquía estructural que surge con Westfalia no es un mero hecho político, sino que también es producto de una decisión teológica fundamental: quitarle a Dios la soberanía y autoridad supremas que jerarquizaban el sistema medieval para dividirlas entre Estados formalmente iguales en situación de anarquía. Segundo, el sistema internacional moderno es nihilista, puesto que con la muerte de Dios ya

\section{Abstract}

This article analyzes the main characteristics of the Westphalian system through the politicaltheological lens of Textos I by Nicolás Gómez Dávila. It is argued that Westphalian States take divine attributes and seize the role God had in the Middle Ages: they claim to be sovereign and assume the ontological and axiological foundation of the system's elements. The results of such analysis are several. Firstly, it is shown that the structural anarchy that is born with Westphalia is not a mere political arrangement but the product of a fundamental theological decision: to take from God the ultimate sovereignty and authority that stablished medieval hierarchy and thus creating a situation of equally sovereign States in anarchy. Secondly, the international modern system is nihilist, in the sense that with the death or exclusion of God there is no absolute order of things, but a situation in which the sole will of States decides what has

doi:10.11144/Javeriana.papo21-2.swat

* Artículo de reflexión.

** Universidad de Granada (Granada, España). Correo electrónico: tomas.molina123@gmail.com 
no hay un orden absoluto de las cosas, sino una situación en la que solo la fuerza de la voluntad estatal decide lo que tiene valor o no. Tercero, la diferencia interpretativa que hay entre Gómez Dávila y las narrativas tradicionales puede leerse como una lucha ideológica por darle contenido a un significante vacío en el sentido de Žižek. Finalmente, la postura de Gómez Dávila podría leerse como una hermenéutica de la sospecha que desvela los aspectos teológicos ocultos en un fenómeno aparentemente secular como el sistema westfaliano.

\section{Palabras clave}

teología política; Westfalia; Nicolás Gómez Dávila; soberanía; modernidad; Carl Schmitt; decisión; Edad Media; religión; sistema internacional moderno; realismo; Morgenthau; Leo Gross; Žižek

\section{Cómo citar este artículo:}

Molina, T. F. (2016). El sistema westfaliano: un análisis desde la teología política de Nicolás Gómez Dávila. Papel Político, 21(2), 411-434. https://doi.org/10.11144/Javeriana. papo21-2.swat value or not. Thirdly, the interpretative difference between Gómez Dávila and the traditional narratives can be read as an ideological struggle to fill the contents of an empty signifier in the vein of Žižek. Finally, it is argued that Gomez Davila's posture can be read as an hermeneutics of suspicion that unveils the hidden theological aspects of an apparently purely secular phenomenon such as the modern international system.

\section{Keywords}

Political theology; Westphalia; Nicolás Gómez Dávila; sovereignty; Modernity; Carl Schmitt; desition; Middle Ages; religion; modern international system; realism; Morgenthau; Leo Gross; Žižek 


\section{Introducción}

Nicolás Gómez Dávila (1913-1994) es uno de los filósofos más importantes en la historia de Colombia. Su obra, aunque solo consta de unos pocos libros, es muy grande en términos poéticos y filosóficos. Sobre su calidad estética tenemos el testimonio de Álvaro Mutis (1988) cuando nos decía que no conocía "antecedentes en castellano de una más transparente y hermosa eficacia de estilo” (p. 23). Y sobre su profundidad filosófica tenemos a Franco Volpi: según el filósofo italiano, Gómez Dávila (2005) era una gema preciosa y un Nietzsche colombiano.

Gómez Dávila, no obstante, era un reaccionario. Eso quiere decir que se oponía sin concesiones a los valores de la modernidad. La democracia, el Estado, la tecnología industrial, el capitalismo y el comunismo le parecen aborrecibles. Por eso, y porque sus comentarios sobre el campo de las relaciones internacionales son muy pocos, puede resultar extravagante que se use para analizar la narrativa tradicional del sistema westfaliano.

Pero la obra de Gómez Dávila es un intento notable de entender la modernidad como fenómeno histórico, político, ético, estético y, sobre todo, religioso. Su valor no se debe solo a la elegancia con la que el bogotano escribía, sino a su postura filosófica misma. El lugar desde el que piensa es muy distinto del que encontramos en las corrientes de pensamiento ilustradas, de manera que ofrece una mirada diferente sobre fenómenos bien estudiados. Mientras el marxismo, por ejemplo, hace una crítica política de la religión para denunciar su carácter ideológico, Gómez Dávila hace una crítica religiosa de la política moderna para denunciar su carácter teológico. En consecuencia, destaca la coloración religiosa de ciertos fenómenos que considerábamos puramente seculares. Por lo anterior, en este artículo, se pretende utilizar la crítica religiosa de Gómez Dávila para descubrir y analizar el carácter teológico del sistema westfaliano.

En la creciente bibliografía que explora el papel de la religión y la teología tanto en Westfalia como en las relaciones internacionales en general podrían mencionarse, por ejemplo, "The religious roots of modern international relations" (Philpott, 2000), "International Political Theology" (Kubálková, 2006) o Christian theology and World Politics (Mia Luoma-Aho, 2013), por no mencionar la inmensa cantidad de artículos y libros sobre el papel de la religión en el terrorismo internacional o en la configuración de identidades y redes de cooperación. No obstante, hasta donde se logra ver aquí, todos los trabajos mencionados realizan su análisis desde una epistemología y ontología modernas. Es decir, funcionan mediante una separación fundamental entre el Ser y lo divino. Uno de los posibles orígenes históricos de esta concepción lo explica John Milbank de la siguiente manera: ${ }^{1}$

\footnotetext{
${ }^{1}$ La tesis de Milbank es extremadamente polémica por, al menos, dos razones. Primero, porque en el mundo griego ya se puede vislumbrar la posibilidad de estudiar al ser sin relación con lo divino. Tucídides sería un buen ejemplo de ello. En segundo lugar, según Remi Brague (2013), el cristianismo mismo ya había enseñado que,
} 
Escoto estableció por primera vez una separación radical de la filosofía de la teología, al declarar que era posible considerar al Ser en abstracción de la cuestión de si era creado o creador. Eventualmente, esto generó la noción de una ontología y una epistemología que no estaban limitadas y antecedían trascendentalmente a la teología misma. En la Edad Media tardía y la modernidad temprana, la filosofía se convirtió en la persecución de esa ontología y esa epistemología y la Reforma no hizo nada por cambiar esa situación. (2002, pp. 23-24)

Como sugiere Milbank, la ontología moderna no se basa en consideraciones teológicas, porque antecede a la misma teología trascendentalmente. Para la modernidad, el Ser se puede estudiar de manera independiente de Dios. En ese orden de ideas, la política, la naturaleza, etc., se estudian desde una perspectiva totalmente inmanente y secular. Tal vez la explicación más influyente de ese fenómeno sea la de Max Weber. Para Weber, el mundo moderno se caracteriza por cuatro fenómenos interconectados: "el espíritu calculador (Rechnenhaftigkeit), el desencantamiento del mundo (Entzauberung der Welt), la racionalidad instrumental (Zweckrationalität) y el dominio burocrático" (en Löwy y Sayre, 2001, p. 18). Todos, pero sobre todo el segundo, sirven para explicar el "proceso histórico por medio del cual el mundo natural y todas las áreas de la experiencia humana vinieron a ser vividas y entendidas como menos misteriosas" (Jenkins, 2000, p. 12). El desencantamiento del mundo da cuenta, en efecto, de cómo es que el ser humano empezó a entender el mundo sin relación con lo religioso, lo divino y lo sagrado. Pero lo más importante aquí, independiente del aparato conceptual que se utilice para describir y explicar el fenómeno, es que el moderno adoptó “el pragmatismo baconiano: la actitud que dice: ¿̇qué importa cómo se ven las cosas para Dios? Encontremos cómo pueden funcionar para nosotros" (Rorty, 1983).

La propuesta de Gómez Dávila, en cambio, podría caracterizarse como premoderna: ${ }^{2}$ apunta a que es preciso estudiar lo humano con referencia a Dios, pues lo propiamente humano se sustenta en Él y apunta a Él (Gómez Dávila, 2002, p. 50). Por lo anterior, para el pensador bogotano, resulta esencial considerar al Ser (y particularmente al ser humano) con relación a la cuestión de si es creado o creador. Las ciencias del espíritu podrían caracterizar la posición de Gómez Dávila como la de un homo religiosus. Para esta clase de hombre, según Mircea Eliade, "la manifestación de lo sagrado fundamenta ontológicamente el

al menos, los preceptos morales sí pueden conocer sin relación alguna con Dios. De hecho, según Brague, la idea de que Dios es necesario para entender la moral es realmente moderna.

${ }^{2}$ La etiqueta es útil para explicar la intención de Gómez Dávila, pero no es exacta ni carente de problemas. Tal vez, porque, al menos desde una perspectiva historicista, no es posible volver a las formas premodernas de entender el mundo sin la mediación de la visión moderna. En otras palabras, los intentos modernos de regresar al jardín encantado del que hablara Weber siempre se hacen desde una posición histórica y axiológica propia de la modernidad. En ese sentido, la "premodernidad" a la que aspira Gómez Dávila es más romántica que propiamente medieval o antigua. 
mundo" (2015, p. 22). De tal manera, no hay mundo posible sin experiencia de lo divino, ni orden identificable, ni centro: sin dios o dioses todo es caos. El mundo, por tanto, debe entenderse teniendo en cuenta su conexión con lo sagrado.

No obstante, dicha propuesta es extremadamente problemática en el mundo moderno, pues, como se ha señalado, este propone la idea de una lectura secular e inmanente de la realidad. Lo divino pertenece a una esfera que no es lícito confundir ni mezclar con la científica o con la política. Así pues, es tentador oponerse automáticamente a Gómez Dávila. Pero, como dice Gadamer, "el que quiere comprender un texto tiene que estar en principio dispuesto a dejarse decir algo por él. Una conciencia formada hermenéuticamente tiene que mostrarse receptiva desde el principio para la alteridad del texto" (1999, p. 335). En consecuencia, la comprensión de lo que el pensador bogotano dice exige que estemos abiertos a sus tesis, aunque contradigan aquello en lo que creemos. Y una vez nos dejemos decir algo por él, quizá sea posible leer fructíferamente las relaciones internacionales desde sus lentes. El resultado puede no ser revolucionario, pero, sin duda, nos permitirá entender algo que de otro modo tal vez no nos llamaría la atención: los presupuestos teológicos de Westfalia vistos desde una perspectiva religiosa.

Por la dificultad de aplicar un pensamiento que no está pensado para las relaciones internacionales a ese mismo campo, es preciso que el artículo siga un orden riguroso. En primer lugar, se explicará en qué consiste el sistema westfaliano/moderno. En otras palabras, se expondrá el objeto de análisis. El argumento que se desarrolla aquí es bien conocido en la disciplina: el sistema westfaliano está compuesto por Estados soberanos, independientes y formalmente iguales que desarrollan sus relaciones bajo el principio ordenador de la anarquía. En segundo lugar, se explicará brevemente la lógica de la teología política de acuerdo con Gómez Dávila. Se mostrará que consiste en estudiar la política teniendo en cuenta una relación fundamental entre ella y Dios. En tercer lugar, se desarrollará el análisis propiamente dicho del sistema westfaliano a partir de la teología política gomezdaviliana. El argumento esencial aquí es que los Estados asumen los atributos y funciones de Dios al reclamar para sí mismos la soberanía y la fundamentación ontológica y axiológica de los elementos del sistema. Como punto de apoyo, se utilizará el análisis teológico-político que Gómez Dávila hace de la democracia moderna, pues es útil por dos razones. Primero, porque la calidad y rigurosidad del análisis del bogotano sirve de paradigma para el que aquí se pretende. Segundo, porque la premisa teológica básica que Gómez Dávila identifica en la democracia moderna se puede encontrar en el sistema westfaliano (la soberanía humana/estatal). Por tanto, hay algo esencial en común que puede ayudar a entender el problema teológico del sistema westfaliano. Finalmente, se desarrollarán las conclusiones. La primera de ellas es que la anarquía estructural que surge con Westfalia no es un mero hecho político, sino que también es producto de una decisión teológica fundamental: quitarle a Dios la soberanía y autoridad suprema que 
jerarquizaban el sistema medieval para dividirlas entre Estados formalmente iguales en situación de anarquía. La segunda es que el sistema internacional moderno es nihilista, puesto que con la muerte de Dios ya no hay una constitución o un orden absoluto de las cosas, sino una situación en la que solo la voluntad estatal decide lo que tiene valor o no. La tercera consiste en que la diferencia interpretativa que hay entre Gómez Dávila y las narrativas tradicionales puede leerse como una lucha ideológica por darle contenido a un significante vacío en el sentido de Žižek. Finalmente, la postura de Gómez Dávila podría leerse como una hermenéutica de la sospecha que desentraña los aspectos teológicos ocultos en un fenómeno aparentemente secular como el sistema westfaliano.

Aquí se ha escogido analizar el sistema westfaliano, al menos visto desde la perspectiva tradicional/dominante de la disciplina, pues es ampliamente reconocido que este es el paradigma de un sistema internacional moderno. Por tanto, nos dará una mirada general sobre lo que han sido las relaciones internacionales en la modernidad. Teschke (2003), uno de los más importantes estudiosos de Westfalia, señala:

\footnotetext{
Convencionalmente, la cuestión del ascenso del orden internacional moderno es asociada a los tratados de Westfalia. Desde la ciencia política americana, las relaciones internacionales británicas y la filosofía social alemana, la convicción compartida es que el acuerdo westfaliano organizó el orden europeo sobre la base de Estados soberanos que se adherían a principios distintamente modernos de conflicto y cooperación. (p. 3) ${ }^{3}$
}

No se utilizará aquí toda la obra de Gómez Dávila para conseguir el propósito expuesto. Se utilizará principalmente Textos I, libro publicado originalmente en 1959, donde Gómez Dávila expone de manera menos fragmentaria que en el resto de su obra sus tesis antropológicas, existenciales y críticas sobre la democracia, el Estado y la teología política.

\section{La narrativa westfaliana}

La narrativa westfaliana se basa en la idea de que después de la paz de Westfalia el sistema internacional europeo se organizó a partir de Estados soberanos, independientes y formalmente iguales que construían sus relaciones a partir del principio ordenador de la anarquía. Aquí se ha decidido explicar dicha narrativa desde los clásicos: Kissinger, Morgenthau y Leo Gross. Los tres son muy leídos e influyentes en la disciplina, de tal manera que han marcado su desarrollo y sirven para ejemplificar lo que se dice en ella sobre Westfalia. Al menos el último es, según Larkins, el Homero del mito de Westfalia (2009, p. 3). En todo caso, la mirada que predomina aquí, como se puede ver por los dos primeros autores que se han escogido, es la realista.

${ }^{3} \mathrm{~A}$ menos de que se indique lo contrario, todas las citas que se encuentran originalmente en inglés son traducidas por el autor de este artículo. 


\section{De la Edad Media a Westfalia}

Los medievales creían que Dios gobernaba el universo. Dios poseía la soberanía última sobre el mundo (Kern, 1939, p. 10). Además, él era el fundamento final del orden y el valor de todo lo que existe. En la Tierra dos figuras se situaban debajo de él y aspiraban a gobernar con su divina y soberana sanción. Por un lado, el papa aspiraba a ser la autoridad universal en asuntos religiosos; por otro, el emperador aspiraba a ser la autoridad universal en asuntos políticos. En consecuencia, había una jerarquía en las relaciones internacionales medievales: reyes y príncipes estaban sometidos, al menos en teoría, a la autoridad imperial y papal; al mismo tiempo, emperador y papa estaban sometidos a la autoridad de Dios. De hecho, todo el mundo medieval estaba organizado bajo el principio de una jerarquía cósmica con Dios a la cabeza de todo. Como dice Larkins, el orden de la Edad Media seguía el esquema neoplatónico de Dionisio el Areopagita, según el cual había una jerarquía que empezaba con Dios y se desprendía hacia el resto del universo:

Una jerarquía tiene a Dios como su líder de todo entendimiento y acción. Está mirando por siempre a Dios. Una jerarquía lleva en sí misma la marca de Dios. La jerarquía causa que sus miembros se vuelvan imágenes de Dios en todos los respectos, claros y puros espejos que reflejan el brillo de la luz primordial y por supuesto de Dios mismo. (2009, p. 55)

Pero como se ha dicho, debajo de Dios estaban las autoridades terrenales divinamente sancionadas. Larkins cita a Cassirer para explicarlo:

En la vida religiosa encontramos la jerarquía eclesiástica que llega hasta el papa en la cima, a los cardenales, los arzobispos y obispos bajando en las escalas del clero. En el estado el más alto poder está concentrado en el emperador, quien delega su poder a sus inferiores, los príncipes, los duques y todos los demás vasallos. Este sistema feudal es una imagen exacta y contraparte del sistema jerárquico general; es una expresión y un símbolo de ese orden cósmico universal que había sido establecido por Dios y que, por lo tanto, es eterno e inmutable. (2009, p. 58)

Pero, de acuerdo con Kissinger, el sistema westfaliano reemplazó las aspiraciones medievales a la universalidad (1994, p. 56). Es decir, en vez de un papa y un emperador gobernando jerárquicamente los príncipes cristianos, Europa iba a dividirse en entidades que solo respondían a su propia autoridad interna. En el sistema westfaliano, emperador y papa solo tendrían autoridad política legítima en sus propios territorios. Y, al mismo tiempo, los príncipes que antes estaban bajo su tutela serían soberanos en sus propios Estados. Morgenthau lo explica así: 
Para el final de la guerra de los Treinta Años, la soberanía como poder supremo sobre un territorio era un hecho político que singnificó la victoria de los príncipes territoriales sobre la autoridad universal del papa y el emperador, por un lado, y sobre las aspiraciones particulares de los barones feudales, por otro. El habitante de Francia encontró que nadie excepto el poder real podía darle órdenes y obligarlo a cumplirlas. Esta experiencia del ciudadano francés fue reproducida por el rey de Inglaterra o el rey de España. (1948, p. 243)

Después de Westfalia, como dice Morgenthau, el Estado se convirtió en la máxima autoridad sobre su territorio. En el sistema internacional moderno, ni Dios, ni papa, ni emperador tenían la máxima autoridad sobre todos los elementos del sistema. La única forma en la que una autoridad externa podía decidir sobre los asuntos internos de un Estado westfaliano era si el Estado mismo voluntariamente cedía una fracción de su soberanía con ese fin. Pero si el sistema internacional abandonó toda pretensión de jerarquía y de heteronomía, entonces debía ordenarse de otra manera. En efecto, si el papa y el emperador no podían ya regular las relaciones internacionales, los Estados debían buscar un nuevo modo de conseguir la paz y la estabilidad en la anarquía y la autonomía. Según Kissinger,

Con el concepto de unidad colapsando, los Estados emergentes de Europa necesitaron un principio [...] para regular sus relaciones. Lo encontraron en los conceptos de raison d'état y el equilibrio de poder. Uno dependía del otro. Raison d'état significaba que el bienestar de un Estado justificaba cualquier medio para alcanzarlo; el interés nacional suplantó la noción medieval de una moral universal. El equilibrio de poder reemplazó la nostalgia por una monarquía universal con la consolación de que cada Estado, persiguiendo sus propios intereses, de algún modo contribuiría a la seguridad y el progreso de los demás. (1948, p. 58)

Así pues, el sistema internacional moderno se caracteriza por ser anárquico (no hay ya una autoridad suprema) y por estar compuesto por Estados soberanos que dependen de la razón de Estado y el equilibrio de poder para organizarse y convivir. Nadie sostendría, empero, que de un momento a otro el sistema medieval desapareció y dio lugar al moderno. El año 1648 es sencillamente la fecha en la que definitivamente podemos señalar el paso de un mundo a otro. Como dice Leo Gross, "en el campo político marcó el abandono de la idea de una estructura jerárquica de la sociedad y su opción por un nuevo sistema caracterizado por la coexistencia de una multiplicidad de Estados, cada uno soberano dentro de su territorio, iguales todos con respecto a los demás y libres de cualquier autoridad externa" (1948, pp. 29-30). Y al mismo tiempo, Gross reconoce, por ejemplo, que el sistema medieval empezó a debilitarse desde una fecha tan lejana como 843, es decir, desde el Tratado de Verdún. También se debilitó desde el siglo XIII “con el ascenso de comunidades independientes o cuasi independientes en Italia y de 
los Estados nacionales en Inglaterra, España y Francia”. Además, “el gran cisma de la Iglesia $(1378,1417)$ y el ascenso de sectas y eventualmente de la Reforma debilitaron correspondientemente la autoridad del papa" (Gross, 1948, p. 30).

Pero el desmoronamiento de las relaciones internacionales medievales también tiene su origen en el desarrollo de la teoría de la soberanía estatal. Sobre esto último señala Gross lo siguiente: "Uno de los oponentes más tempranos del emperador fue Bartolo de Sassoferrato, que dibujó una fina distinción entre la soberanía de iure del emperador y la existencia de facto de civitates superiorem non recognoscens" (p. 30). Lo que Sassoferrato argumentó era que el emperador tenía autoridad de iure, pero no de facto. La soberanía como hecho político estaba en manos de los gobernantes directos de cada Estado. Dicha distinción luego alcanzaría una forma más exacta y fatal para las pretensiones del emperador: rex in regno suo est Imperator regni sui, estos es, el rey en su reino es emperador en su reino (p. 31). Así pues, el emperador ya ni siquiera tendría la soberanía jurídica. Los legistas, entonces, desempeñaron un papel fundamental contra el poder imperial y en favor de la soberanía de los Estados europeos.

Otro hecho jurídico que terminó de destruir el sistema medieval fue el derecho internacional moderno. Mientras Victoria, Suárez y Gentili negaban la supremacía del emperador, también afirmaban "la existencia de una comunidad internacional gobernada por el derecho internacional” (Gross, 1948, p. 32). Al menos en la forma final que fue adoptada de facto, esta nueva concepción del derecho internacional pretendía ser auténticamente universal, es decir, pretendía que todos los soberanos del mundo pudieran participar de ella, independiente de su política o religión. La universalidad se comprendía aquí horizontalmente, es decir, todos los Estados participaban del derecho en cuanto iguales jurídicamente. En cambio, la vieja concepción medieval, aunque con pretensiones universales, también aplicaba solo "a una sociedad cristiana organizada jerárquicamente, esto es, en la base de la desigualdad” (p. 33).

El nuevo derecho laico podía crear una nueva comunidad de Estados universal y formalmente horizontal. Por eso, Gross nos dice que la paz Westfalia "sin duda promovió la laicización del derecho internacional, al divorciarlo de cualquier trasfondo religioso" (1948, p. 26). Sin laicización sería imposible el sistema de Estados soberanos moderno, porque la autoridad jerarquizante del papa seguiría siendo fundamental, y por tanto, la soberanía de los Estados quedaría en entredicho. Por lo demás, sin laicización el derecho internacional solo podría ser universal en tanto el globo fuese cristiano. En efecto, quizá por eso "del tratado de Westfalia se ha dicho que fue un acto público de negación de la autoridad internacional del papado" (Gross, 1948, p. 28). De tal modo, Westfalia sirvió para ayudar a completar un proceso que les permitiría a los Estados funcionar como entidades formalmente iguales, esto es, unidades que, independiente de su política interna o de su religión, son reconocidas como soberanas e iguales en el derecho internacional. 


\section{El éxito de la narrativa}

La anterior narrativa sobre Westfalia se popularizó, porque, como lo explica Teschke, ayudó a darle a la disciplina de las relaciones internacionales un sentido de "dirección teórica, unidad temática y legitimidad histórica”. De hecho, la narrativa westfaliana goza de "una línea de aceptación tácita que corre a través de la literatura, pasada sin ser examinada, de generación en generación”. Por eso, tanto los “realistas, los miembros de la escuela inglesa, así como los constructivistas", comparten la idea de que "los tratados de Westfalia constituyeron un punto de cambio decisivo en la historia de las relaciones internacionales" (2003, p. 2).

Según Larkins, las razones del triunfo de la narrativa son las siguientes:

Aunque el mito de Westfalia en las relaciones internacionales está muchas veces en conflicto con los eventos históricos y las condiciones políticas y sociales del tiempo, su aura en general goza de buena salud. Una de las razones es que Westfalia tiene un significado que va más allá de los intereses inmediatos de las relaciones internacionales. Para muchos, denota el momento en el cual la política, habiendo pasado varios siglos en las cavernas oscuras de la cristiandad medieval, emergió a la luz de la racionalidad moderna. Westfalia simbolizó la transformación de un sistema de gobierno basado en estructuras jerárquicas de la cristiandad medieval, a uno ordenado respecto de Estados independientes y soberanos: una transición de jerarquía a anarquía. (2009, p. 4)

La narrativa convencional sobre Westfalia, no obstante, ha sido duramente criticada en los últimos años, sobre todo desde la sociología histórica. Por ejemplo, en su importante libro The myth of 1648 (2003), Blenno Teschke argumenta que la paz de Westfalia no constituye un cambio fundamental en las relaciones internacionales y que solo hasta tiempos relativamente recientes podemos ver un sistema de Estados moderno. ReusSmit, citado por Hobden (2002), argumenta: “En 1648 las concepciones premodernas y dinásticas de las relaciones internacionales estaban en apogeo; la concepción moderna de soberanía solo emergió a nivel internacional en el siglo XIX. Es más: en 1648 ningún Estado tenía soberanía interna” (p. 266).

Sin embargo, en este artículo, no se tendrán en cuenta dichas críticas. Lo que interesa aquí son los supuestos teológico-políticos del entendimiento clásico o convencional del sistema westfaliano. Por eso, este artículo se basará en la narrativa convencional de la disciplina, esto es, la misma que Teschke y Reus-Smit critican.

\section{Teología política}

La ontología religiosa de Gómez Dávila consiste esencialmente en señalar que todo lo propiamente humano tiene una relación sin solución de continuidad con lo divino (2002, 
p. 50). Por eso, no se puede considerar la cuestión humana sin referencia al problema de si el hombre es creador o creado por Dios, ni, por lo mismo, de cuáles son sus respectivas posiciones ontológicas en el universo. Si se pudiese, entonces sería obvio que el hombre no tendría una relación fundamental ${ }^{4}$ con lo sagrado, esto es, sería irrelevante si es hijo de dios o dios mismo. En consecuencia, desde esta perspectiva religiosa, la comprensión de la política misma depende de un entendimiento cabal de la relación que hay entre ella y Dios. En ese sentido, se habla aquí de teología política.

Ejemplifiquemos. La soberanía es un elemento esencial de los Estados modernos, tanto desde una perspectiva jurídica como empírica. Las decisiones que los Estados toman muchas veces se justifican con referencia a su condición soberana inalienable. Lo que se añade a esta postura desde la teología política es que la soberanía no se puede explicar sin referencia a una cuestión teológica, puesto que "una noción de Dios, explícita o tácita, es el contexto final” que la ordena (Gómez Dávila, 2002, p. 61). Si un Estado se declara soberano, está aceptando implícitamente que no hay ningún poder por encima del suyo, pues la soberanía es autonomía absoluta. En ese sentido, la noción de Dios que ordena y da sentido a la soberanía es la de su inexistencia o subordinación al Estado mismo, en cuanto un Dios que esté por encima del Estado invalidaría su soberanía, al menos desde la perspectiva gomezdaviliana. ${ }^{5}$ El Estado, a su vez, se estará apropiando de las características del creador, pues Dios es el soberano, esto es, la fuente última e inapelable de autoridad y decisión. La soberanía del Estado implica así una decisión frente a Dios: está por debajo del Estado mismo o no existe.

Veamos otro ejemplo. Desde la postura del bogotano, todo individuo, como toda comunidad, tiene una noción de Dios o de su negación que ordena sus actos políticos (Gómez Dávila, 2002, p. 61). La comunidad política se puede organizar de acuerdo con las leyes dictadas por la revelación divina, las normas de la razón humana, o puede encontrar un punto medio entre ambas. Pero en todos los casos la relación con Dios es insoslayable para la comprensión, pues todos presuponen una teología política particular. Verbigracia, si la comunidad política decide no organizarse de acuerdo con la revelación o las normas del derecho natural, presupone que Dios no existe o que su importancia es muy limitada, irrelevante o incluso dañina en los asuntos públicos

\footnotetext{
${ }^{4}$ Aquí vale la pena señalar que la expresión fundamental se usa con toda su fuerza literal: para Gómez Dávila, el hombre es hombre solo mientras reconozca la existencia de Dios. Lo divino fundamenta al hombre, pues su contacto con Él provoca el nacimiento de la razón, de los valores, y de todo lo que separa al hombre de los animales (Gómez Dávila, 2002, pp. 46-53).

${ }^{5}$ Para Gómez Dávila, la soberanía del Estado es un capítulo de la religión antropoteísta democrática, en la que la soberanía humana invade las funciones propias de Dios, incluso la función redentora que Dios antes tenía en el campo religioso. De ese modo, al menos la soberanía moderna, por sus implicaciones y sus pretensiones, sí entra en conflicto con Dios (2002, pp. 58 y 77).
} 
de la comunidad. Así pues, tiene ya una idea de la relación política entre Dios y el hombre, es decir, una teología política. ${ }^{6}$

Podría señalarse aquí que la comprensión teológico-política aporta poco al entendimiento científico de la política, ya que la cuestión de la relación entre el hombre y Dios solo importa a los creyentes para quienes la ontología no precede trascendentalmente a Dios. En ese sentido, lo científico consistiría en hacer un análisis de la identidad y las percepciones de los creyentes, pero no un análisis desde la perspectiva teológica de un creyente. Desde una perspectiva moderna, esa es una posición válida y razonable. Sin embargo, la hermenéutica de Gómez Dávila muestra precisamente cuál es una posible mirada de las personas religiosas sobre el tema de las relaciones entre ideologías políticas y religión en la modernidad: las ideologías políticas que proclaman la soberanía del hombre son religiones estrictas. Gómez Dávila lo ve así: si el hombre es soberano no reconoce una autoridad por encima de la suya y debe asumir la función axiológica y ontológica que Dios asumía antes (2002, p. 68). La soberanía del hombre, por tanto, implica una postura ante Dios (debe negarlo para ser auténticamente soberano) y una apropiación de funciones sagradas (el mundo debe seguir teniendo sentido y fundamentación).

Lo anterior no implica que el ángulo religioso sea más objetivo que el modernosecular. Gómez Dávila sabía que su pensamiento está “demasiado consciente de fundarse sobre evidencias circunscritas, sobre raciocinios cuya validez se confina en determinados universos de discurso" (2002, p. 55). Incluso Schmitt confesaba que la teología política demanda una confesión antropológica de fe (Vinx, 2016). De tal modo, los inventores de esta postura analítica son conscientes de su carácter parcial. Sin embargo, el análisis sigue teniendo valor desde la secularidad. Finalmente, como ya se ha dicho, es una ventana a la mentalidad religiosa: quienes quieran entender las reservas no solo de ciertos grupos católicos frente al mundo moderno, sino también de musulmanes, etc., podrán sacar provecho de la teología política tal y como se entiende aquí.

En todo caso, es preciso estudiar cuál es la relación entre la teología y la narrativa del sistema westfaliano para entender este último desde la hermenéutica religiosa aquí propuesta. Según Gómez Dávila, “sólo el análisis religioso [...] nos esclarece la naturaleza del fenómeno y nos permite atribuirle [...] su dimensión exacta. Procediendo de distinta manera, nunca logramos establecer su definición genética, ni mostrar la coherencia de sus formas, ni relatar su historia” (2002, p. 62). No pretendiendo tanto, empero, aquí meramente se propone como posibilidad interpretativa que arroja luz sobre el fenómeno.

${ }^{6}$ Al privatizar la religión, es decir, al relegar la religión a un asunto puramente privado sin influencia legítima en lo público, el liberalismo clásico tendría una teología política, al menos desde esta perspectiva. 


\section{Análisis teológico-político}

En Textos I, Nicolás Gómez Dávila hace un análisis de la democracia a partir de las suposiciones ya explicadas de su ontología religiosa y su teología política. Pero la esencia de la democracia para Gómez Dávila es la misma esencia de la modernidad: la creencia en que el hombre es soberano, esto es, la creencia en la autonomía y autosuficiencia de la voluntad humana. Lo dice así en un escolio: "Creer en la soberanía del hombre es el rasgo característico del moderno" (2005, p. 30). Que ese sea el rasgo definitorio del moderno todavía no es un análisis religioso, ni mucho menos novedoso. Ya Adorno y Horkheimer destacaban en La dialéctica de la Ilustración que el propósito del programa definitorio de la modernidad, esto es, de la Ilustración, es el de convertir a los hombres en señores de todo: en soberanos (2002, p. 1). Lo que aporta Gómez Dávila es una comprensión religiosa de ese hecho, esto es, su aporte está en destacar que la soberanía humana no es un mero acontecimiento secular, sino que esconde una posición religiosa estricta en la que el hombre asume el papel de Dios. En todo caso, el análisis de la democracia de Gómez Dávila nos sirve para entender religiosamente otros fenómenos típicamente modernos, como el sistema nacido de Westfalia, ya que se basan en la misma suposición básica: la soberanía humana. Por lo anterior, aquí se conectará el análisis de la democracia de Gómez Dávila con el sistema westfaliano.

Según el análisis de Gómez Dávila, la “democracia es una religión antropoteísta. $\mathrm{Su}$ principio es una opción de carácter religioso, un acto por el cual el hombre asume al hombre como Dios. Su doctrina es una teología del hombre-dios; su práctica es la realización del principio en comportamientos, en instituciones y en obras [las cursivas son mías]" (2002, p. 62). Para Gómez Dávila, la premisa fundamental que sustenta la teología democrática del hombre-dios es la autonomía absoluta del hombre, esto es, su soberanía.7 Soberano es aquel que no reconoce una autoridad por encima de la suya. Ser soberano implica que se puede ser lo que uno quiera, pues no hay nada que lo predetermine. El hombre, en este sentido, se da su propia ley y su propio destino.

¿Pero por qué la soberanía humana implica una teología? En primer lugar, porque solo es posible negando a Dios y su propia soberanía. Pero veamos el problema con más detalle. Desde una perspectiva moderna, el hombre simplemente rechaza la soberanía divina y se atribuye la suya propia sin divinizarse. Lo religioso simplemente ya no tiene importancia o la tiene solo desde el ámbito de lo privado. Desde la perspectiva religiosa de Gómez Dávila, sin embargo, la soberanía humana tiene un costo: el rechazo de Dios y la divinización

7 En Textos I, Gómez Dávila plantea la soberanía democrática respecto de una voluntad autónoma: "Para que el hombre sea dios, es forzoso atribuirle la voluntad como esencia, reconocer en la voluntad el principio y la materia misma de su ser. La voluntad esencial, en efecto, es suficiencia pura. La voluntad esencial es atributo tautológico de la autonomía absoluta" (2002, p. 64). 
del hombre. ${ }^{8}$ La divinización consiste en asumir las funciones que Dios tenía en la Edad Media. Es preciso recordar cuáles eran las principales: la redención humana, la soberanía y la fundamentación ontológica y axiológica del mundo. Como se verá más adelante con mayor detalle, Gómez Dávila piensa que el hombre moderno cree redimirse a partir del progreso, cree ser soberano rechazando la soberanía divina y asumiéndola y cree asumir la fundamentación ontoaxiológica9 del mundo (2002, p. 68). Tal vez una comparación con Schmitt ayude a clarificar este problema con respecto a su implicancia política. Desde el punto de vista del jurista alemán, uno podría decir lo siguiente:

Si Dios es el centro del mundo religioso, un mundo político que muestra la misma estructura, se centrará alrededor del soberano, esto es, ocupará su misma posición "estructural”. Esto nos lleva a la pregunta: ċsi la posición estructural de Dios puede, por vía de la secularización, ser transferida a la teoría moderna del Estado, ¿̇no es porque la posición estructural era, para empezar, una posición política? (Norris, 2000, p. 13)

Desde Gómez Dávila se plantearía una pregunta distinta: ¿si la posición estructural de Dios puede ser transferida a la teoría moderna del Estado, ¿no es porque la teoría moderna del Estado era, para empezar, una posición teológico-religiosa? Es decir, para Gómez Dávila, la similitud esencial entre la idea moderna de soberanía y la teología no es estructural, ni el fruto de un proceso de secularización: en realidad, la similitud está en que la soberanía humana/estatal es una posición donde el hombre se asume a sí mismo como Dios, es decir, asume una posición en la que el hombre toma la función que antes le correspondía a Dios.

Exploremos con más cuidado el problema de la soberanía estatal desde la perspectiva teológica, pues aquí es donde reside uno de los aspectos fundamentales del análisis teológico-político del sistema westfaliano. Gómez Dávila afirma: "El estado que se estima solo juez de sus actos e instancia final de sus pleitos, que no acata sino la norma que su voluntad adopta, y cuyo interés es la suprema ley, puede constituirse en dios" (2002, p. 78). En efecto, la soberanía es el primer y más importante atributo

\footnotetext{
${ }^{8}$ Señala Gómez Dávila: "Vencer nuestro atroz infortunio es el más natural anhelo del hombre, pero sería irrisorio que el animal menesteroso, a quien todo oprime y amenaza, confiara en su sola inteligencia para sojuzgar la majestad del universo, si no se atribuyese una dignidad mayor y un origen más alto" $(2002$, p. 58$)$.

${ }^{9}$ La lectura de Heidegger sobre el paso de la Edad Media a la modernidad nos indica: "La reducción cartesiana del ser verdadero (y del verdadero ser) a la certeza del sujeto no fue otra cosa que [...] la reducción del ser a la representación cierta del ego cogito [...], la reducción del ser a la voluntad del sujeto" (Pacheco, 2012, p. 35). Y en efecto, reducir el ser (en cuanto ser-valor) a la voluntad del sujeto es para Gómez Dávila una de las características esenciales del hombre democrático moderno (2002, p. 68 y 99). En todo caso, para Gómez Dávila, esa reducción falla en su propósito de fundamentar el mundo sin Dios. El hombre moderno está reducido así a una condición animal (p. 53).
} 
de Dios que el Estado se apropia, pues sin ella no podría decidir de manera inapelable sobre lo bueno y lo malo, sobre el Ser, etc.

Que el Estado es soberano en el sistema internacional moderno "lógicamente implica que es independiente y que no hay ninguna autoridad por encima de él. Consecuentemente, cada Estado es libre de manejar sus asuntos internos y externos a discreción" (Morgenthau, 1948, p. 245). Pero dicha soberanía se deriva precisamente del hecho de que la teoría moderna del Estado ya implicaba una posición teológica religiosa. El Estado asume también características de Dios. Según el teólogo calvinista A. W. Pink, la soberanía divina tiene las siguientes características:

La soberanía de Dios puede ser definida como el ejercicio de su supremacía. Siendo infinitamente elevado sobre la más alta creatura, Él es el más alto, señor del cielo y de la tierra. Sujeto a nadie, influenciado por nadie, absolutamente independiente. Dios hace lo que quiere, solo lo que quiere siempre lo que quiere. Nadie puede limitarlo. Su misma palabra expresamente declara: "Mi consejo permanecerá y haré según mi voluntad" (Is 46-10). (2009, p. 34)

Por tanto, cuando Gómez Dávila indica que el Estado soberano es un dios no es una simple exageración. Desde su lectura religiosa, se puede reconocer que el Estado soberano asume la misma característica de Dios, pues no reconoce ninguna autoridad exterior a él y por eso mismo es absolutamente independiente en sus determinaciones. Nadie externo puede limitarlo. Hace lo que quiere, solo lo que quiere, siempre lo que quiere. Como explica Morgenthau, el "Estado tiene el derecho de darse a sí mismo cualquier constitución que quiera, crear cualquier ley que desee independiente de sus efectos sobre sus propios ciudadanos, y de escoger cualquier sistema de administración. Es libre de crear cualquier sistema militar que determine necesario para los propósitos de su política exterior que, a su vez, es libre de determinar como lo crea correcto" (1948, p. 244).

No es de extrañar, pues, que, como señala Schmitt,

en la teoría del Estado del siglo XVII, el monarca es identificado con Dios y tiene en el Estado una posición exactamente análoga a la que se le atribuye a Dios en el sistema cartesiano del mundo [...]. Un hilo continuo corre por todas las concepciones metafísicas, políticas y sociológicas que postulan al soberano como una unidad personal y un creador primigenio. (1985, p. 46)

Como fuerza suprema e independiente, el Estado soberano se confirió a sí mismo la capacidad de determinar lo que es justo e injusto, bueno o malo, y por tanto negó la posibilidad de un criterio externo de verdad y justicia. El poder del Estado soberano en consecuencia se volvió absoluto, en el sentido de que, ya que no contó con límites externos 
últimos, nada está por encima de él. La soberanía es incontestable o no es soberanía. La soberanía pura no tiene límites exteriores auténticos; como mucho, temporales y voluntarios. Si los tuviera, no sería la máxima autoridad.

Lo que se muestra aquí con la soberanía del hombre y del Estado no es la retención de una manera de pensar en una situación distinta, como en la tesis de la secularización, ni tampoco se trata de una mera similitud estructural entre teología y política, donde el soberano ocupa el mismo lugar en la política que Dios ocupaba dentro del universo religioso. Por eso, el bogotano escribe que "la divinidad que la democracia atribuye al hombre no es figura de retórica, imagen poética, hipérbole inocente, en fin, sino definición teológica estricta" (2002, pp. 61, 62). En ese sentido, lo que el pensador bogotano desvela es que el hombre no ocupa un lugar como el de Dios en una situación secular o no religiosa, sino que literalmente está ocupando el lugar de Dios dentro de una nueva religión: el antropoteísmo. En otras palabras, el hombre no se da atributos estructuralmente similares a los de Dios, sino los atributos y funciones de Dios: la soberanía y la fundamentación del mundo.

Ahora bien, lo anterior es problemático cuando se aplica al sistema westfaliano, pues la función de Dios también era la de organizar una jerarquía y, como se ha visto, el sistema internacional moderno es formalmente anárquico. En el mundo moderno, no hay una cadena del ser que legitime y le dé sentido a la situación política. Cuando el Estado soberano ocupa el lugar que Dios tenía en el sistema internacional medieval, lo hace en un sentido distinto, precisamente porque la estructura moderna es distinta de la medieval: es anárquica y no jerárquica. Cada Estado soberano funciona con la soberanía propia de un dios, y cuando interactúa con los demás Estados, trata de fundamentar ontológica y axiológicamente los demás elementos del sistema, como Dios lo hacía antes. Un ejemplo de esto último: un Estado moderno no es reconocido como tal porque Dios lo mande así, como en la Edad Media, sino porque la mirada y la voluntad de otros Estados así lo determina..$^{10}$ En otras palabras, un Estado es reconocido como Estado porque él mismo se autorreconoce y porque otros Estados lo reconocen así. En el terreno internacional, solo tiene el estatuto legítimo de Ser lo que los Estados soberanos reconocen así. La mirada de los Estados tiene entonces una función ontológica esencial.

A partir del lente teológico-político, podría afirmarse que las condiciones históricas que hicieron posible el sistema westfaliano no solo se derivan de las provisiones formales de los tratados que lo constituyeron, ni solo del desarrollo político y jurídico de la idea de soberanía, sino que se derivan del contexto religioso más amplio del proyecto de la modernidad. Solo cuando el hombre pretendió sustituir a Dios en el mundo, solo cuando el universo humano se volvió totalmente antropocéntrico y el hombre decidió

${ }^{10}$ Aquí el Estado asumiría el rol del sujeto en el sistema cartesiano leído desde Heidegger: su voluntad fundamenta el ser de los entes en el sistema internacional, en el sentido de que le da realidad y lo justifica. 
que podía asumir las funciones ontológicas y axiológicas de Dios, pudo, en fin, surgir algo como un sistema de Estados soberanos. Podría uno decir que si los hombres creyesen todavía en el papel que Dios tenía antes en la estructura del mundo, un sistema de Estados soberanos sería imposible, al menos de iure, porque la soberanía última seguiría en manos de Dios. De tal modo, habría al menos una estructura jerárquica nominal y la soberanía propiamente no existiría o tendría otra forma mucho menos absoluta.

Precisamente por lo último puede decirse que la anarquía no es simplemente una condición dada, sino la consecuencia de una decisión religiosa. En la Edad Media, el papa y el emperador estaban por encima de los príncipes, pero la soberanía última estaba en manos de Dios. Por tanto, había una jerarquía que empezaba con Dios. En el sistema westfaliano, en cambio, al menos desde la perspectiva realista, no hay ninguna autoridad por encima de los Estados: todos son iguales. Precisamente por eso hay anarquía: no hay una autoridad final que garantice el orden. Es posible decir que la anarquía (de iure, al menos) nace de la negación de la autoridad suprema y final de Dios. En ese sentido, el problema de la anarquía no es meramente político sino también teológico.

Después de elaborar la tesis de la soberanía como divinización del hombre, Gómez Dávila procede a explicar las "cuatro tesis ideológicas de (la) apologética" democrática (2002, p. 65). Como se insiste aquí, el hombre soberano (y por extensión el Estado) asume no solo la función estructural de Dios dentro de la política, sino que asume funciones propias de Dios, como dar fundamento ontológico al mundo. Esas funciones se desarrollan en las tres últimas tesis. La primera es meramente preparatoria: negar a Dios. En efecto, la primera tesis ideológica de la apologética es la del ateísmo. Para que el hombre sea soberano, es preciso que Dios no exista. "Si Dios existiese, el hombre sería su criatura [...] El Dios trascendente anula nuestra inútil rebeldía" (Gómez Dávila, 2002, p. 66). Pero lo mismo sucede con la narrativa westfaliana: los Estados solo pueden ser soberanos si no son la criatura de un Dios. Suponer que un Estado depende de la voluntad divina implica que no es soberano, al menos en el sentido propio de la modernidad. Empero, no es que los Estados soberanos hayan comprobado la irrealidad de Dios: el problema es que es un estorbo para ellos. Al menos desde esta perspectiva, la soberanía divina choca con las pretensiones de autonomía absoluta de los Estados.

La segunda tesis ideológica es la idea del progreso. El progreso es la promesa irrefutable de que en el futuro el hombre será cada vez más como el ideal de sus sueños. ${ }^{11}$ El hombre se convierte en un demiurgo que "elabora el alimento de su epifanía futura” (Gómez

\footnotetext{
${ }^{11}$ En sentido estricto, al menos desde la mirada trágico-realista, el progreso es difícil o imposible dentro del sistema westfaliano. No obstante, desde la mirada moderna, hay un paso adelante, esto es, progreso, cuando se pasa del sistema medieval al westfaliano. En efecto, en la modernidad el Estado por fin es libre de formular su política exterior "objetivamente", a partir de principios puramente racionales, sin la supuesta fantasía propia de la Edad Media. Eso tiene como consecuencia un mejor orden internacional.
} 
Dávila, 2002, p. 67). El hombre alcanzará la perfección material y espiritual gracias a su propio esfuerzo racional. El hombre, pues, ya no necesita la redención divina: al contrario, él mismo se encarga de darse a sí mismo todo lo que necesita. De manera similar, una vez la autoridad jerárquica y trascendente del papa y el emperador desaparece gradualmente tras 1648, los Estados se ven obligados a sobrevivir gracias a su propio esfuerzo racional. Ya no pueden depender de la intervención divina, de la jerarquía religiosa, o de una jerarquía natural de seres. Así pues, deben desarrollar la idea del interés nacional y formularlo de manera racional y lógica. En ese sentido, los Estados westfalianos asumen las funciones protectoras y estabilizadoras que Dios tenía en la Edad Media.

En tercer lugar, tenemos la teoría de los valores. Para Gómez Dávila, esta es la más espinosa, porque "la presencia de valores es hecho que anula los postulados democráticos con insolencia tranquila” (2002, p. 67). Si los valores existen independiente del hombre, entonces el hombre no es dios ni soberano. "Si la verdad nos ata a una naturaleza de las cosas, si el bien obliga como un llamamiento irresistible, si la belleza existe en la pulpa del objeto", entonces el hombre apenas es "un viajero taciturno entre misterios; el hombre atraviesa los dominios de un incógnito monarca”. El demócrata, entonces, debe sostener que el valor apenas es "lo que la voluntad reconoce como suyo". En otras palabras, valor es lo que el hombre reconoce como valor. El hombre moderno es el creador de los valores. "Pero las teorías más usuales eligen rutas menos obvias. La función biológica, o la forma social, suplantan la voluntad desnuda, y representan su manifestación concreta” (p. 68). Así pues, la belleza cumple una función biológica, el bien cumple una función social evolutiva. Pero esas teorías más usuales no son "más que artefactos ideológicos" (p. 69). En todo caso, es preciso resaltar que, si el hombre es el creador de los valores, entonces el hombre asume la función axiológica fundacional que antes asumía la divinidad. En otras palabras, el hombre se arroga para sí mismo la función de ordenar y darle valor al mundo de lo humano.

En el sistema westfaliano, lo anterior se traduce en que los Estados son libres de decidir qué norma internacional tiene valor y, por tanto, qué norma merece ser obedecida. Como explica Morgenthau, "ninguna regla del derecho internacional es vinculante, excepto aquellas que (el Estado) ha creado para sí por medio del consentimiento” (1948, p. 244). Si el Estado decide crear u obedecer una norma, es porque está en su interés nacional. Nadie puede decidir por él y nadie puede darle leyes si el Estado no lo acepta primero. Por lo mismo, "ningún Estado puede ser invocado en una corte internacional sin su consentimiento" (p. 244). Desde esta perspectiva, una regla de derecho internacional tiene validez solo cuando una voluntad estatal la reconoce como suya (al menos desde la mirada realista). Pero si el Estado es el creador del valor, entonces también está asumiendo una función que antes tenía Dios dentro del mundo: decidir sobre lo bueno y lo malo, lo justo y lo injusto. 
En cierto sentido, empero, los Estados están obligados a acatar un valor: la supervivencia; la razón es sencilla: sin vida no se pueden perseguir otros objetivos. No obstante, como los Estados son voluntades soberanas, pueden decidir libremente cuál será su interés nacional más allá de la supervivencia. El contexto histórico influirá en la decisión de cuál será el interés nacional, pero aparte de la supervivencia no hay ningún imperativo natural, ningún imperativo que anteceda la existencia misma del Estado, porque eso supondría que una voluntad exterior lo determina, esto es, que la esencia del Estado no es la voluntad libre y soberana. Como dice Hooker, explicando a Schmitt, el Estado soberano "tiene el espacio y la libertad moral de examinar el mundo exterior con un ojo frío e independiente, y puede 'escoger' actuar en cualquier manera que le convenga” (2009, p. 20).

"La última tesis de la apologética democrática es el determinismo universal" (Gómez Dávila 2002, p. 69). Si el universo no es una máquina determinada de antemano, entonces "aun el empeño más tenaz, más inteligente y más metódico, puede fracasar ante la naturaleza inescrutable de las cosas" (p. 69). Por supuesto, el hombre no puede asumir el papel divino de crear las leyes de la naturaleza; lo que sí puede hacer es tratar al mundo exterior como un ser predecible por el hombre. No obstante, el determinismo universal abrogaría la libertad soberana del hombre. De tal modo, "la doctrina recurre, para esquivar la contradicción que la anula, a una acrobacia metafísica que transporta al hombre, desde su pasividad de objeto, hasta una libertad de dios repentino" (p. 79). En el caso del sistema westfaliano, podemos razonar de manera análoga: para que en un sistema internacional carente de soberanía divina haya orden, tiene que haber una realidad predecible a partir de unos principios básicos: el derecho internacional, el interés nacional, la razón de Estado y el equilibrio de poder. $\mathrm{Al}$ mismo tiempo, los Estados hacen una acrobacia metafísica que los transporta de meros objetos en el sistema a sujetos soberanos.

En suma, las cuatro tesis de la apologética democrática tienen su encarnación en las características del sistema westfaliano. De tal manera, puede sostenerse que los Estados soberanos toman el antiguo lugar de Dios. Para que eso pueda darse, su esencia debe ser la voluntad soberana, esto es, la autonomía humana. Por eso, es preciso negar que cualquier voluntad preceda la del Estado, sobre todo la de Dios. Si hay una voluntad exterior sobre la que el Estado tiene poder, es solo porque el Estado mismo se la ha dado. Segundo, el Estado es capaz de controlar y mejorar su destino ahora que no depende de ninguna voluntad exterior a él. En ese sentido, los Estados crean un orden ontológico óptimo para sí mismos. Tercero, el sistema westfaliano supone que el Estado es libre de crear y escoger los valores que considere convenientes. Así pues, los Estados fundamentan el valor de los valores del derecho internacional. Cuarto, el sistema westfaliano pone en marcha ciertos principios que deben funcionar de manera predecible, como si fueran decretados por un Dios, para que los Estados puedan cumplir sus propósitos mediante el derecho internacional, el interés nacional, la razón de Estado y el equilibrio de poder. 


\section{Conclusiones}

Como se ha visto a lo largo del artículo, desde la perspectiva de Gómez Dávila la doctrina de la soberanía westfaliana se basa en una teología política. Eso se debe a que el Estado intenta tomar las funciones de Dios: reclama para sí la soberanía y el papel de fundamentación ontológica y axiológica. Hay una aclaración importante que debe hacerse aquí, empero. Por un lado, es claro que la soberanía sobre todo el sistema queda vacante, al menos en sentido estricto, porque no hay ningún Estado tan poderoso como para asumirla. En ese sentido, en la práctica no hay ningún Estado que pueda destronar a Dios para ocupar exactamente su misma posición estructural. En realidad, en el sistema internacional moderno la soberanía última se encarna en cada una de las unidades: cada Estado asume la función soberana que antes tenía Dios dentro de su respectivo territorio y frente al sistema. Para ser más claros: cada Estado toma los atributos de Dios (poseedor de la soberanía, fundamentador del mundo, etc.), pero dentro de una nueva estructura nominalmente horizontal.

Es posible decir que, a partir del análisis teológico-político, en el sistema westfaliano los Estados y sus legistas se convierten en los creadores del derecho internacional, en vez de obedecer una ley que los antecede trascendentalmente; el Estado se convierte en el dador de valor, en vez de obedecer los valores objetivos de la divinidad; los Estados organizan ontológicamente el sistema internacional mediante sus interacciones, en vez de recibir un orden de Dios. Pero como se ha dicho, todo lo anterior solo es posible si al mismo tiempo se niega que Dios pueda ejercer poder político en este mundo. La autoridad soberana del Estado solo es posible si Dios no está encima de ella. De tal modo, Dios ha muerto en la teología política del sistema internacional moderno mucho antes de que Nietzsche lo proclamara. De manera nietzscheana deberíamos ver, entonces, cuál es la consecuencia principal de la muerte de Dios en las relaciones internacionales.

Podríamos sostener que el orden internacional westfaliano es nihilista ${ }^{12}$. Sin una fuente suprema de valores, sin un orden absoluto del mundo, no hay realmente una jerarquía axiológica más allá de la que los Estados decreten mediante la fuerza de su voluntad. Objetivamente nada importa. ¿Por qué esto es nihilismo? Al menos de acuerdo con Nietzsche, "que no hay verdad; que no hay una constitución absoluta de las cosas, una cosa en sí: esto mismo es nihilismo, es incluso el nihilismo extremo. Coloca el valor de las cosas precisamente en que a ese valor no le corresponde ni le correspondió

\footnotetext{
${ }^{12}$ Esa, sin embargo, podría ser una lectura apresurada. Siempre y cuando haya una estructura ideológica fuerte que le dé sentido a la realidad, los Estados podrán estar comprometidos con causas. ¿No están los Estados modernos plenamente comprometidos con la causa del capitalismo y el desarrollo económico? Podría decirse que sí, pero que en todo caso seguirían siendo nihilistas, pues el capitalismo es solo un reflejo de un deseo de bienestar económico. Pero el hecho de que estén dispuestos a tantos sacrificios (recursos naturales, no cuidar su propia población, etc.) en nombre del capitalismo, deja ver que quizá la causa del capitalismo es más radical y fuerte que el mero conformismo que postuló Nietzsche. En ese orden de ideas, podrían no ser nihilistas.
} 
ninguna realidad, sino que es sólo un síntoma de fuerza por parte de quien instituye el valor" (2006, p. 242). Pero sin un orden externo dado por Dios, el Estado soberano, como el último hombre de Nietzsche, no tendría ninguna gran pasión o compromiso y su único objetivo sería sobrevivir cómodamente, o aumentar su poder for power's sake. Eso tiene una ventaja, por supuesto, como lo han visto los realistas: cuando los Estados tienen grandes pasiones como las cruzadas, suelen arruinarse. Por tanto, es mejor para el orden político convencional que los Estados tengan objetivos modestos y realizables. Pero también tiene la desventaja de que hay un vacío axiológico en el sistema. Solo vale lo que la voluntad soberana de los Estados reconoce como suyo. ${ }^{13}$

Es preciso señalar aquí la contradicción fundamental entre la lectura de Gómez Dávila y la lectura secular del problema. La objeción de Gómez Dávila al mundo moderno (iel hombre soberano equivale a un dios!) contradice la respuesta moderna (no, ya no es posible hablar de dioses; el hombre es meramente soberano). Evidentemente, se trata de visiones que dependen de un campo ideológico particular, de una visión de mundo desde la cual una u otra respuesta tiene sentido. Pero un relativismo convencional ${ }^{14}$ quizá no tenga aquí ninguna penetración filosófica; quizá no nos ayude a entender la radical contradicción entre ambas posiciones. Por eso, la perspectiva de Žižek puede ser muy útil.

Es posible afirmar aquí, a partir de Žižek, que la "soberanía” es un significante vacío que puede ser llenado por contenido particular nuevo a través de la lucha ideológica. El filósofo esloveno pone el ejemplo de la democracia para explicar este punto:

Por medio del proceso, la referencia al significante "democracia" es una constante, y la lucha ideológica consiste precisamente en la lucha para imponer significados nuevos en este término (por ejemplo decir que la democracia que no es inclusiva con las mujeres, que no evita la esclavitud de los trabajadores, que no incluye también respeto por las minorías religiosas, étnicas, sexuales, etc., no es una verdadera democracia). La misma plasticidad del contenido significante (la lucha por lo que la democracia "verdaderamente significa") se basa en el carácter fijo del significante vacío "democracia". (2009, p. 119)

Así pues, no es que exista entonces un significante (la soberanía, en este caso), cuyo contenido se interpreta de maneras distintas, sino que, al contrario, el significante está propiamente vacío y se llena desde distintas posiciones ideológicas. Su definición aceptada depende de quien logre la hegemonía sobre el concepto. En la Edad Media, por ejemplo, la idea de soberanía dependía de Dios. Hoy, en cambio, se acepta que es una cuestión puramente humana y política. Pero la incompatibilidad de ambas posiciones no

\footnotetext{
${ }^{13}$ De nuevo, se hace notar aquí que eso es cierto especialmente desde la mirada realista.

${ }^{14}$ Es decir, la idea de que son posiciones igualmente válidas; dos interpretaciones desde dos puntos de vista simétricos.
} 
sería aquí simplemente el fruto de una lectura distinta de la realidad, sino el producto de la lucha sobre lo que verdaderamente significa la "soberanía”. En ese sentido, la interpretación religiosa sería la perdedora de la lucha por la hegemonía en Occidente. Empero, el interés en Gómez Dávila no sería solo el de entender, con actitud de anticuario, la posición que perdió validez hace siglos, sino resaltar precisamente que con la posición radical de Gómez Dávila queda en evidencia que la “soberanía” es un significante vacío.

El análisis de Gómez Dávila también nos podría ayudar a entender si vivimos todavía en un mundo westfaliano. Si es cierto que la apropiación de las funciones de Dios es la característica principal de los estados westfalianos; esto es, si los Estados reemplazan a Dios en su función de amo que fundamenta el mundo mismo, entonces los Estados representan lo que "Lacan llamaba en el Seminario XVII el discurso del Amo. En estos regímenes autoritarios, la palabra y la voluntad del Rey o amo [...] era soberana -la fuente de autoridad política, sin derecho posible a cuestionarla" (Sharpe, s. f.). La cuestión aquí entonces no es tanto el asunto formalmente ontológico de si hay actores aparte del Estado en el sistema internacional, sino el estatuto ontológico del Estado y los demás actores hoy: en otras palabras, la cuestión está en si hay actores alternativos que puedan poner en duda el carácter de amo del Estado. En caso de que el Estado no tenga la última palabra (si su soberanía está de facto o de iure en duda), entonces podríamos hablar de un desmoronamiento del orden del amo, que es la característica esencial del sistema westfaliano.

Existe otra forma de leer la interpretación de Gómez Dávila. En su influyente libro Freud y la filosofía (1970), el filósofo francés Paul Ricoeur explica que Marx, Nietzsche y Freud son paradigmas de lo que puede caracterizarse como la hermenéutica de la sospecha. Lo fundamental en dicha hermenéutica es la tesis de que los pensamientos directos que una persona expresa muchas veces ocultan significados que son diferentes de e incluso contrarios a los significados que la persona cree expresar.

Podría decirse que Nicolás Gómez Dávila también utiliza la hermenéutica de la sospecha, aunque sus conclusiones sean radicalmente diferentes de las de Marx, Nietzsche y Freud. Los cuatro buscaban, siguiendo el carácter de su hermenéutica, hacer visibles los significados y pensamientos ocultos de sus objetos de estudio. Pero mientras los tres pensadores de habla alemana encontraron que detrás de la religión había solo intereses humanos (ideología, resentimiento y debilidad ontológica), Gómez Dávila encuentra algo muy distinto. El colombiano descubre que detrás de fenómenos históricos como la soberanía hay una religiosidad oculta incluso para quienes la promueven y que es contraria a la máscara oficial que posee.

Finalmente, la hermenéutica de la sospecha ayudaría a resolver la dificultad más grande que se encuentra en el análisis de Gómez Dávila: la concepción más moderna de soberanía humana es explícitamente secular e indiferente a los asuntos religiosos. Pero 
mediante una hermenéutica de la sospecha uno podría desentrañar el significado religioso oculto en la soberanía moderna: es decir que implica una decisión esencialmente religiosa donde el hombre se asume como Dios.

\section{Referencias}

Adorno, T. y Horkheimer, M. (2002). Dialectic of enlightenment. Stanford, CA: Stanford University Press.

Brague, R. (2013). The impossibility of secular society. First Things, 236, 27-31.

Eliade, M. (2015). Lo sagrado y lo profano. Barcelona: Paidós.

Gadamer, H. (1999). Verdad y método. Salamanca: Sígueme.

Gómez Dávila, N. (2001). Escolios a un texto implícito, selección. Bogotá: Villegas.

Gómez Dávila, N. (2002). Textos I. Bogotá: Villegas.

Gómez Dávila, N. (2003). Notas. Bogotá: Villegas.

Gómez Dávila, N. (2005). Escolios a un texto implícito. Bogotá: Villegas.

Gross, L. (1948). The Peace of Westphalia, 1648-1948. The American Journal of International Law, 42(1), 20-41.

Hobden, S. (2002). Historical sociology of international relations. Cambridge, UK: Cambridge University Press.

Hooker, W. (2009). Carl Schmitt's international thought: Order and orientation. Cambridge, UK: Cambridge University Press.

Jenkins, R. (2000). Disenchantment, enchantment and re-enchantment: Max Weber at the millennium. Max Weber Studies, 1(1), 11-32.

Kern, F. (1939). Kingship and law in the middle ages: I. The divine right of kings and the right of resistance in the early middle ages. Oxford: Blackwell.

Kissinger, H. (1994). Diplomacy. Nueva York: Simon \& Schuster.

Kubálková, V. (2006). International political theology. The Brown Journal of World Affairs, 12(2), 139-150.

Larkins, J. (2009). From hierarchy to anarchy: Territory and politics before Westphalia. Nueva York: Palgrave Macmillan.

Löwy, M. y Sayre, R. (2001). Romanticism against the tide of modernity. Durham, NC: Duke University Press. 
Luoma-aho, M. (2013). God and international relations: Christian theology and world politics. Londres: Bloomsbury Academic.

Milbank, J. (2002). Radical orthodoxy: A new theology. Londres: Routledge.

Morgenthau, H. (1948). Politics among nations: The struggle for power and peace. Nueva York: Knoph.

Mutis, Á. (1988). Donde se vaticina el destino de un libro inmenso. Revista del Colegio Mayor de Nuestra Señora del Rosario, 81(542), 23-24.

Nietzsche, F. (2006). Fragmentos póstumos. Madrid: Tecnos.

Norris, A. (2000). Carl Schmitt's Political Metaphysics: On the Secularization of "the Outermost Sphere”. Theory \& Event, 4(1).

Pacheco, N. (2012). La lectura heideggeriana de la metafísica de Descartes. Revista de Filosofía Factótum, 9, 33-42.

Philpott, D. (2000). The religious roots of modern international relations. World Politics, 52(2), 206-245.

Philpott, D. (2014). Sovereignty. En The Stanford Encyclopedia of Philosophy. Stanford, CA: Stanford University.

Pink, A. (2009). The attributes of God. Auckland: Floating Press.

Ricœur, P. (1970). Freud and philosophy. New Haven: Yale University Press.

Rorty, R. (1983). Against Belatedness. London Review of Books, 5(11), 3-5.

Schmitt, C. (1985). Political theology: Four chapters on the concept of sovereignty. Cambridge, Mass.: MIT Press.

Sharpe, M. (s. f.). Slavoj Žižek. En Internet Encyclopedia of Philosophy. Recuperado de http://www.iep.utm.edu/zizek/\#Hb

Strauss, L. (2006). The political philosophy of Hobbes, its basis and its genesis. Chicago: University of Chicago Press.

Teschke, B. (2003). The myth of 1648: Class, geopolitics, and the making of modern international relations. Londres: Verso.

Vinx, L. (2016). Carl Schmitt. En The Stanford Encyclopedia of Philosophy. Stanford, CA: Stanford University.

Žižek, S. (2009). The plague of fantasies. Londres: Verso. 